\title{
CONSERVACIÓN in vitro DE GERMOPLASMA DE Agave spp. BAJO CONDICIONES DE CRECIMIENTO RETARDADO
}

\section{In vitro CONSERVATION OF Agave spp. GERMPLASM UNDER SLOW GROWTH CONDITIONS}

\author{
Eugenio Pérez Molphe Balch*, Mayra J. Esparza Araiza y Martha E. Pérez Reyes
}

Unidad de Biotecnología Vegetal, Centro de Ciencias Básicas, Universidad Autónoma de Aguascalientes. Av. Universidad 940. 20131, Aguascalientes, Ags., México. Tel. (449) 9108400.

*Autor para correspondencia (eperezmb@correo.uaa.mx)

\section{RESUMEN}

Se desarrolló un sistema de conservación in vitro en condiciones de crecimiento retardado para las especies Agave bracteosa, A. chiapensis, A. nizandensis, A. ornithobroma, A. peacockii, A. titanota y A. victoria reginae, consideradas como amenazadas, y para $A$. cupreata, $A$. karwinskii y A. potatorum, explotadas de manera no sostenible para la elaboración de mezcal. El objetivo fue disponer de una herramienta que permita la conservación a mediano plazo de germoplasma de estas especies. Se demostró que la adición de agentes osmóticos al medio de cultivo (manitol o sorbitol $50 \mathrm{~g} \mathrm{~L}^{-1}$ ) es capaz de reducir la tasa de crecimiento in vitro de los tejidos, medida como incremento en peso fresco, y prolongar así el tiempo entre subcultivos de $75 \mathrm{~d}$ a 10 meses, y sin afectar su viabilidad ni su capacidad de regenerar plantas completas en medios con citocininas y sin los agentes osmóticos. Se obtuvieron eficiencias de regeneración de entre 5.8 y 20.6 brotes por explante en tejidos conservados durante 10 meses con la adición de agentes osmóticos. Los brotes generados formaron raíces y se adaptaron a suelo con eficiencias de 92 y $80 \%$ en promedio, respectivamente. Se concluye que con este sistema es posible establecer a mediano plazo bancos de germoplasma in vitro que contribuyan a la conservación y uso racional de estas especies.

Palabras claves: Agave spp., almacenamiento in vitro, banco de germoplasma, crecimiento retardado, especies amenazadas.

\section{SUMMARY}

An in vitro conservation system under slow growth conditions was developed for the threatened species Agave bracteosa, A. chiapensis, A. nizandensis, A. ornithobroma, A. peacockii, A. titanota y A. victoria reginae, and for non-sustainably exploited species A. cupreata, A. karwinskii and A. potatorum, used for "mezcal" production. The objective was to provide a tool for medium-term germplasm conservation of these species. The addition of osmotic agents to the culture media (manitol or sorbitol at $50 \mathrm{~g} \mathrm{~L}^{-1}$ ) reduces in vitro tissue growth rate, measured as fresh weight increase. The slow growth rate extends lapses between subcultures from $75 \mathrm{~d}$ to 10 months without affecting their viability or complete plant regeneration capacity in media with cytokinins and without osmotic agents. Regeneration efficiencies between 5.8 and 20.6 shoots per explant were obtained in tissues conserved during $\mathbf{1 0}$ months with the addition of osmotic agents. Regenerated shoots were rooted and adapted to soil with 92 and $80 \%$ average efficiencies, respectively. It is concluded that with this system, it is possible to establish in vitro germplasm banks, in the medium term, that contribute to the conservation and rational use of these species.

Index words: Agave spp., germplasm bank, in vitro storage, slow growth, threatened species.

\section{INTRODUCCIÓN}

El género Agave se distribuye en el continente americano, en el que se encuentran aproximadamente 200 especies. De éstas, 150 habitan en México, por lo que este es el país que cuenta con la mayor riqueza en este grupo (García-Mendoza, 2007). Estas plantas han sido utilizadas para múltiples fines desde la época prehispánica, y actualmente son fuente de materias primas para industrias importantes como las de bebidas alcohólicas y de fibras naturales (Gentry, 1982; Eguiarte-Fruns y González-González, 2007). Sus usos como fuente alimenticia, material para la construcción y como ornamentales en el paisajismo natural en espacios privados o públicos, se están extendiendo rápidamente debido a su belleza, a su bajo consumo de agua y al poco mantenimiento que requieren.

Son pocas las especies de Agave que han sido domesticadas y cultivadas. Este es el caso de A. angustifolia (maguey espadilla) y A. tequiliana (agave azul), usadas para la producción de mezcal y tequila; y de $A$. fourcroydes (henequén) y A. sisalana (sisal) para la extracción de fibras. Sin embargo, la mayoría de las especies del género, si bien son explotadas aún no se han domesticado. En estos casos los ejemplares se extraen de las poblaciones naturales, casi siempre de una manera no sostenible. Actualmente varias especies de Agave se encuentran amenazadas debido a esta sobreexplotación, por lo que la Norma Oficial Mexicana NOM-059-SEMARNAT-2010 incluye a 18 de ellas en la lista de plantas en peligro, amenazadas o sujetas a protección especial. Esto hace necesario el tomar medidas concretas y eficaces para garantizar la conservación de estas especies y a la vez permitir su explotación racional.

La biotecnología vegetal ofrece una serie de técnicas que pueden ser incorporadas a los esquemas de conservación de especies amenazadas, entre las que destacan las relacionadas con el cultivo in vitro de tejidos vegetales. Así, países con una biodiversidad importante, como Malasia, Brasil y España, ya están incorporando estas tecnologías 
como herramientas para la conservación de su flora (González-Benito y Martín, 2011; Noor et al., 2011; Pilatti et al., 2011). Una primera aplicación del cultivo in vitro es la propagación masiva, técnica que permite obtener una gran cantidad de plantas en tiempos y espacios reducidos. Esta metodología se ha desarrollado ya para varias especies del género Agave, y ha demostrado ser más eficiente que cualquiera de los métodos convencionales de propagación que se manejan en este grupo de plantas (Enríquez del Valle et al., 2005; Aureoles-Rodríguez et al., 2008; DomínguezRosales et al., 2008a; Ramírez-Malagón et al., 2008).

Otra aplicación del cultivo in vitro que podría resultar importante en el caso de los agaves, y que es complementaria a las técnicas de propagación masiva, es la conservación por tiempo indefinido de tejidos vivos. Éstos pueden mantenerse bajo condiciones controladas de luz y temperatura para constituir bancos de germoplasma in vitro. En condiciones normales, el mantenimiento de cultivos viables por tiempo indefinido requiere de subcultivos frecuentes con la finalidad de renovar los nutrientes del medio, y dividir los tejidos que se han desarrollado. Esto genera un costo considerable por el tiempo de trabajo y medios de cultivo que deben emplearse, además de que cada vez que los cultivos son manipulados existe el riesgo de pérdida de los mismos por contaminación.

Para evitar estos inconvenientes, se han desarrollado sistemas de crecimiento retardado cuyo objetivo es prolongar los periodos entre subcultivos para facilitar y abaratar la conservación a mediano plazo de cultivos viables in vitro. Para disminuir la tasa de crecimiento de los tejidos sin afectar su viabilidad, además del control de las condiciones de luz y temperatura, se ha utilizado un estrés osmótico controlado. Esto se logra agregando al medio de cultivo compuestos químicos como el manitol o sorbitol que reducen el potencial osmótico del mismo, y por tanto la disponibilidad de agua para los tejidos, sin alterar el balance bioquímico de las células vegetales. También se puede reducir la tasa de crecimiento mediante inhibidores del crecimiento como el ácido abscísico o el ácido N-dimetilaminosuccinámico en el medio (Lynch 1999; Sarasan et al., 2006).

La técnica de conservación in vitro de germoplasma ha mostrado ser eficiente en varias especies cultivadas, en algunas de las cuales ya se usa de forma rutinaria (Engelmann, 2011). Este es el caso de la papa (Solanum tuberosum L.) (Westcott, 1981), manzano (Malus domestica / Malus sylvestris) (Negri et al., 2000) y caña de azúcar (Saccharum officinalis L.) (Watt et al., 2009), entre otros. Obviamente, para que esta técnica de conservación pueda aplicarse, los tejidos almacenados deben mantener su capacidad de regenerar plantas completas una vez que son retirados del siste- ma de crecimiento retardado, lo cual se ha demostrado en todas las especies mencionadas. Como puede verse, estos sistemas son una alternativa biotecnológica relativamente sencilla y de bajo costo para la conservación a mediano plazo de germoplasma vegetal.

Sin embargo, a pesar de las ventajas que presenta esta metodología, se ha desarrollado poco para especies silvestres amenazadas, a pesar de que puede ser un complemento adecuado para los programas de conservación in situ. No hay reportes de la aplicación de esta técnica en los agaves, o en general en especies de la flora mexicana. El objetivo de este trabajo fue evaluar el efecto del manitol y el sorbitol en la conservación in vitro de 10 especies silvestres del género Agave, siete de las cuales están incluidas en la NOM059-SEMARNAT-2010 debido al grado de amenaza que enfrentan. Esta técnica se puede incluir en las estrategias de conservación en los bancos de germoplasma in vitro y como alternativa en la conservación y uso racional de estas especies.

\section{MATERIALES Y MÉTODOS}

Material vegetal. Se emplearon brotes generados in vitro, de 45 a 50 d de edad, de las especies Agave bracteosa S. Wats. ex Engelm, A. chiapensis Jacobi, A. cupreata Trel. \& Berger, A. karwinskii Zucc., A. nizandensis Cutak, A. ornithobroma Gentry, A. peacockii Croucher, A. potatorum Zucc., A. titanota Gentry, y A. victoria reginae T. Moore (Cuadro 1). Estos brotes se generaron cultivando explantes con los meristemos basales en medios con citocininas (Cuadro 2), como parte del programa de propagación masiva in vitro de estas especies que se desarrolla en la Unidad de Biotecnología Vegetal de la Universidad Autónoma de Aguascalientes. El tipo y concentración de citocinina adecuado para la proliferación in vitro de brotes para cada especie se definió en trabajos previos (Domínguez-Rosales et al., 2008a; Domínguez-Rosales et al., 2008b).

Efecto de agentes osmóticos en la tasa de crecimiento in vitro. Para estos experimentos se tomaron brotes generados in vitro de 30 a $50 \mathrm{~mm}$ de altura, de tamaño lo más homogéneo posible dentro de cada especie. El medio de cultivo utilizado en todos los casos fue el MS completo, con las sales, vitaminas y compuestos orgánicos que lo constituyen (Murashige y Skoog, 1962). El pH del medio fue ajustado a 5.7 y se adicionaron con $30 \mathrm{~g} \mathrm{~L}^{-1}$ de sacarosa y $8 \mathrm{~g} \mathrm{~L}^{-1}$ de agar (PhytoTechnology Laboratories) como gelificante. Se utilizaron frascos de cultivo de $460 \mathrm{~mL}$ de capacidad con tapa de polipropileno (Biotecnológica Sierra Morena), que contenían $100 \mathrm{~mL}$ de medio de cultivo y que se esterilizaron en autoclave a $121{ }^{\circ} \mathrm{C}$ por $18 \mathrm{~min}$. A los brotes se les eliminaron las raíces y la parte distal de las hojas, y las porciones basales así obtenidas se sembraron en posición 
Cuadro 1. Distribución, situación dentro de la Norma Oficial Mexicana NOM-059-SEMARNAT-2010 y uso principal de las especies de Agave incluidas en el trabajo.

\begin{tabular}{llcl}
\hline Especie de Agave & Distribución & NOM-059-SEMARNAT-2010 & Uso principal \\
\hline A. bracteosa & Coahuila y Nuevo León (Endémico) & $\mathrm{A}$ & Ornamental \\
A. chiapensis & Chiapas (Endémico) & $\mathrm{Pr}$ & Ornamental \\
A. cupreata & Guerrero y Michoacán & --- & Elaboración de mezcal \\
A. karwinskii & Oaxaca y Puebla (Endémico) & --- & Elaboración de mezcal \\
A. nizandensis & Oaxaca (Endémico) & $\mathrm{P}$ & Ornamental \\
A. ornithobroma & Nayarit y Sinaloa & $\operatorname{Pr}$ & Ornamental \\
A. peacockii & Puebla (Endémico) & $\operatorname{Pr}$ & Obtención de fibras \\
A. potatorum & Oaxaca y Puebla & --- & Elaboración de mezcal \\
A. titanota & Oaxaca (Endémico) & $\operatorname{Pr}$ & Ornamental \\
A. victoria reginae & Coahuila y Nuevo León (Endémico) & $\mathrm{P}$ & Ornamental
\end{tabular}

" $\mathrm{Pr}=$ sujeta a protección especial; $\mathrm{A}$ = amenazada; $\mathrm{P}$ = en peligro.

Cuadro 2. Capacidad de regeneración in vitro en explantes de Agave conservados por 10 meses en medio basal (testigo) y en medio con manitol y sorbitol, y eficiencia de enraizamiento y supervivencia en suelo de los brotes generados.

\begin{tabular}{|c|c|c|c|c|c|c|}
\hline \multirow{2}{*}{ Especie } & \multirow{2}{*}{ Citocinina ${ }^{\llbracket}$} & \multicolumn{3}{|c|}{ Brotes por explante बा $^{\pi}$} & \multirow{2}{*}{$\begin{array}{c}\text { Enraiza- } \\
\text { Miento }(\%)^{\mathrm{x}}\end{array}$} & \multirow{2}{*}{$\begin{array}{c}\text { Super- } \\
\text { vivencia }(\%)^{\mathrm{x}}\end{array}$} \\
\hline & & Testigo & Manitol & Sorbitol & & \\
\hline A. bracteosa & $1.0 \mathrm{BA}$ & $7.6 \mathrm{a}$ & $8.3 \mathrm{a}$ & $7.1 \mathrm{a}$ & $97 \pm 5.2$ & $82 \pm 3.6$ \\
\hline A. chiapensis & $0.5 \mathrm{BA}$ & $8.1 \mathrm{a}$ & $9.2 \mathrm{a}$ & $7.8 \mathrm{a}$ & $87 \pm 4.8$ & $76 \pm 3.8$ \\
\hline A. cupreata & $1.5 \mathrm{BA}$ & $9.4 \mathrm{a}$ & $9.2 \mathrm{a}$ & $7.3 \mathrm{~b}$ & $93 \pm 5.6$ & $80 \pm 4.6$ \\
\hline A. karwinskii & $1.5 \mathrm{BA}$ & $5.7 \mathrm{a}$ & $6.1 \mathrm{a}$ & $5.8 \mathrm{a}$ & $98 \pm 3.6$ & $78 \pm 4.8$ \\
\hline A. nizandensis & $1.0 \mathrm{BA}$ & $8.1 \mathrm{a}$ & $7.6 \mathrm{a}$ & $7.9 \mathrm{a}$ & $88 \pm 6.1$ & $86 \pm 3.4$ \\
\hline A. ornithobroma & $0.5 \mathrm{BA}$ & $11.3 \mathrm{a}$ & $8.4 \mathrm{~b}$ & $7.8 \mathrm{~b}$ & $94 \pm 3.7$ & $78 \pm 3.5$ \\
\hline A. peacockii & $0.5 \mathrm{BA}$ & $17.1 \mathrm{a}$ & $15.4 \mathrm{ab}$ & $13.2 \mathrm{~b}$ & $95 \pm 6.0$ & $74 \pm 4.9$ \\
\hline A. potatorum & $3.0 \mathrm{CIN}$ & $7.8 \mathrm{a}$ & $7.2 \mathrm{a}$ & $7.6 \mathrm{a}$ & $94 \pm 4.7$ & $82 \pm 6.1$ \\
\hline A. titanota & $1.0 \mathrm{BA}$ & $6.9 \mathrm{a}$ & $7.2 \mathrm{a}$ & $6.6 \mathrm{a}$ & $90 \pm 4.3$ & $80 \pm 3.6$ \\
\hline A. victoria reginae & $5.02 \mathrm{iP}$ & $21.3 \mathrm{a}$ & $19.4 \mathrm{a}$ & $20.6 \mathrm{a}$ & $86 \pm 2.8$ & $84 \pm 4.0$ \\
\hline
\end{tabular}

vertical, introduciendo su extremo inferior en el medio.

Los recipientes de cultivo, ya con los brotes, se sellaron con cinco capas de película autoadherible de PVC (Vitafilm) y se mantuvieron bajo luz fluorescente ( 54 umol fotón $\mathrm{m}^{-2} \mathrm{~s}^{-1}$ ), con un fotoperiodo de $16 \mathrm{~h}$ de luz y 8 de oscuridad, a $25 \pm 2{ }^{\circ} \mathrm{C}$. Los agentes osmóticos probados para retardar el crecimiento mediante su adición al medio de cultivo, fueron manitol $\left(50 \mathrm{~g} \mathrm{~L}^{-1}\right)$ o sorbitol $\left(50 \mathrm{~g} \mathrm{~L}^{-1}\right)$ (ambos SigmaAldrich). El efecto de estos dos tratamientos se determinó en la tasa de crecimiento in vitro de los brotes; como testigo se usó el medio basal sin agentes osmóticos.

Para esto, se midió el peso fresco inicial de los brotes y el peso fresco a los 15, 30, 45, 60 y 75 d de incubación. Con este fin, los brotes se sacaron del recipiente de cultivo y se pesaron en la campana de flujo laminar, e inmediatamente después se regresaron al mismo recipiente, el cual se selló nuevamente y se regresó a las condiciones de incubación. Para cada especie trabajada se utilizaron 10 brotes por tratamiento y 10 más para el testigo. Se colocaron dos a cuatro brotes por recipiente (según la especie).

Se utilizó un diseño experimental completamente al azar y el experimento completo se realizó cuatro veces para cada especie. Los datos obtenidos se conjuntaron y se analizaron mediante análisis de varianza (ANDEVA). Las medias se compararon mediante la prueba de Tukey $(\mathrm{P} \leq 0.05)$, con el fin de determinar si los tratamientos afectaron significativamente el incremento en peso fresco de los tejidos cultivados in vitro. 
Efecto de la conservación in vitro en condiciones de crecimiento retardado en la capacidad de regeneración. Los brotes sometidos a los tratamientos antes mencionados se incubaron por un total de 10 meses bajo las mismas condiciones. En el caso del testigo, los tejidos se subcultivaron a medio fresco cada $75 \mathrm{~d}$ durante el mismo periodo, mientras que los tejidos sometidos a los tratamientos no se subcultivaron. Pasado este tiempo, se tomaron explantes de estos tejidos para probar su capacidad para regenerar plantas completas. Para esto, se eliminaron las hojas y las raíces, y la porción restante que contenía tejidos meristemáticos fue sembrada en medio MS a pH 5.7, adicionado con $30 \mathrm{~g} \mathrm{~L}^{-1}$ de sacarosa, $8 \mathrm{~g} \mathrm{~L}^{-1}$ de agar y la citocinina que en trabajos previos se determinó como la más eficiente para la generación de brotes en cada especie (Domínguez-Rosales et al., 2008b) (Cuadro 2).

Se sembró un total de 20 explantes provenientes de cada tratamiento, y del testigo, por cada especie trabajada. Se utilizó un diseño completamente al azar. El experimento completo se hizo dos veces. Los cultivos se mantuvieron bajo las mismas condiciones de incubación antes descritas por 50 d, y pasado este tiempo se determinó el número de brotes generado por explante. Los datos obtenidos se conjuntaron y analizaron mediante ANDEVA, y la comparación entre las medias se hizo con la prueba de Tukey $(\mathrm{P} \leq 0.05)$ con el fin de determinar si los sistemas de crecimiento retardado empleados afectaron la capacidad de regeneración de los tejidos almacenados durante 10 meses.

Los brotes generados en estos experimentos fueron separados del explante original y trasferidos a medio MS a 50 $\%$, a pH 5.7, adicionado con $15 \mathrm{~g} \mathrm{~L}^{-1}$ de sacarosa y $8 \mathrm{~g} \mathrm{~L}^{-1} \mathrm{de}$ agar, en el que se incubaron por $45 \mathrm{~d}$ a $25 \pm 2{ }^{\circ} \mathrm{C}$ bajo luz continua $\left(54 \mu \mathrm{mol}\right.$ fotón $\left.\mathrm{m}^{-2} \mathrm{~s}^{-1}\right)$, con el fin de inducir su enraizamiento. Éste se cuantificó como porcentaje de brotes que generaron un sistema radical vigoroso (más de tres raíces de al menos $3 \mathrm{~cm}$ de largo). Las plantas generadas fueron aclimatadas y transferidas a suelo con la metodología previamente desarrollada (Domínguez-Rosales et al., 2008b). La supervivencia de las plantas en suelo se determinó a los $45 \mathrm{~d}$ de su transferencia, mediante el porcentaje de plantas vivas y en crecimiento activo (que estaban produciendo nuevas hojas).

\section{RESULTADOS Y DISCUSIÓN}

Se observaron diferencias en las tasas de crecimiento in vitro en medio basal entre las especies estudiadas (Figuras 1 y 2), sin considerar los tratamientos con agentes osmóticos. El peso fresco de los explantes iniciales fue similar en todos los casos, entre 0.1 y 0.3 g. Después de 75 d de incubación los explantes de A. victoria-reginae incrementaron su peso hasta $0.9 \mathrm{~g}$ en promedio, especie que mostró la menor tasa de crecimiento, o hasta $4.72 \mathrm{~g}$ en promedio en A. nizandensis, la de mayor tasa de crecimiento. El resto de las especies estuvieron dentro de este intervalo.

Lo anterior quiere decir que la tasa de crecimiento in vitro difiere entre las especies incluidas en el trabajo, lo cual puede ser un reflejo de su tasa de crecimiento in vivo, o bien indica que algunas especies satisfacen mejor que otras sus necesidades nutricionales en el medio basal utilizado . Al tiempo de incubación indicado, el agotamiento del medio fue evidente en la mayoría de los recipientes testigo.

En todas las especies estudiadas se encontró que al menos uno de los tratamientos con los agentes osmóticos probados redujo significativamente la tasa de crecimiento in vitro a los $75 \mathrm{~d}$ de incubación, en comparación con la tasa de crecimiento de la misma especie en medio basal testigo. En las Figuras 1 a 2 se muestran las curvas de crecimiento de los brotes (medido como incremento en peso fresco), cultivados en medio testigo y en presencia de manitol o sorbitol. En todos los casos puede verse una menor tasa de crecimiento en los medios adicionados con los agentes osmóticos. Los compuestos usados en este trabajo, manitol y sorbitol, así como la concentración probada, se seleccionaron con base en reportes para otras especies en las que estos sistemas de conservación de germoplasma ya están bien estudiados (Sarkar y Naik, 1997; Gopal et al., 2002).

En este trabajo, en el caso de Agave bracteosa, A. cupreata, A. karwinskii, A. ornithobroma, A. potatorum, y A. titanota, tanto el manitol como el sorbitol causaron este efecto. En A. nizandensis, A. peacockii y A. victoria-reginae, sólo el manitol redujo de manera significativa $(\mathrm{P} \leq 0.05)$ la tasa de crecimiento. Finalmente, en $A$. chiapensis sólo el sorbitol causó este efecto. No existen antecedentes de trabajos de este tipo con el género Agave, aunque en algunas especies de cactáceas del género Turbinicarpus se ha observado también que responden de manera similar al manitol y al sorbitol usados como agentes osmóticos para retardar el crecimiento, mientras que otras lo hacen sólo a uno de ellos (Pérez-Molphe-Balch et al., 2012).

Los brotes de agave mantenidos en presencia de agentes osmóticos no mostraron señales de daño ni alteraciones en su morfología, como puede verse en las Figuras 3 y 4, sino sólo un menor crecimiento. En otras especies se ha reportado que los agentes osmóticos empleados para retardar el crecimiento, ocasionan cierta mortalidad de los tejidos durante el periodo de almacenamiento. Por ejemplo, en papa la supervivencia de explantes después de 12 meses de almacenamiento fue de entre 12 y $67.6 \%$, esto en tratamientos con manitol y sorbitol similares a los utilizados en este trabajo (Gopal, 2002). 

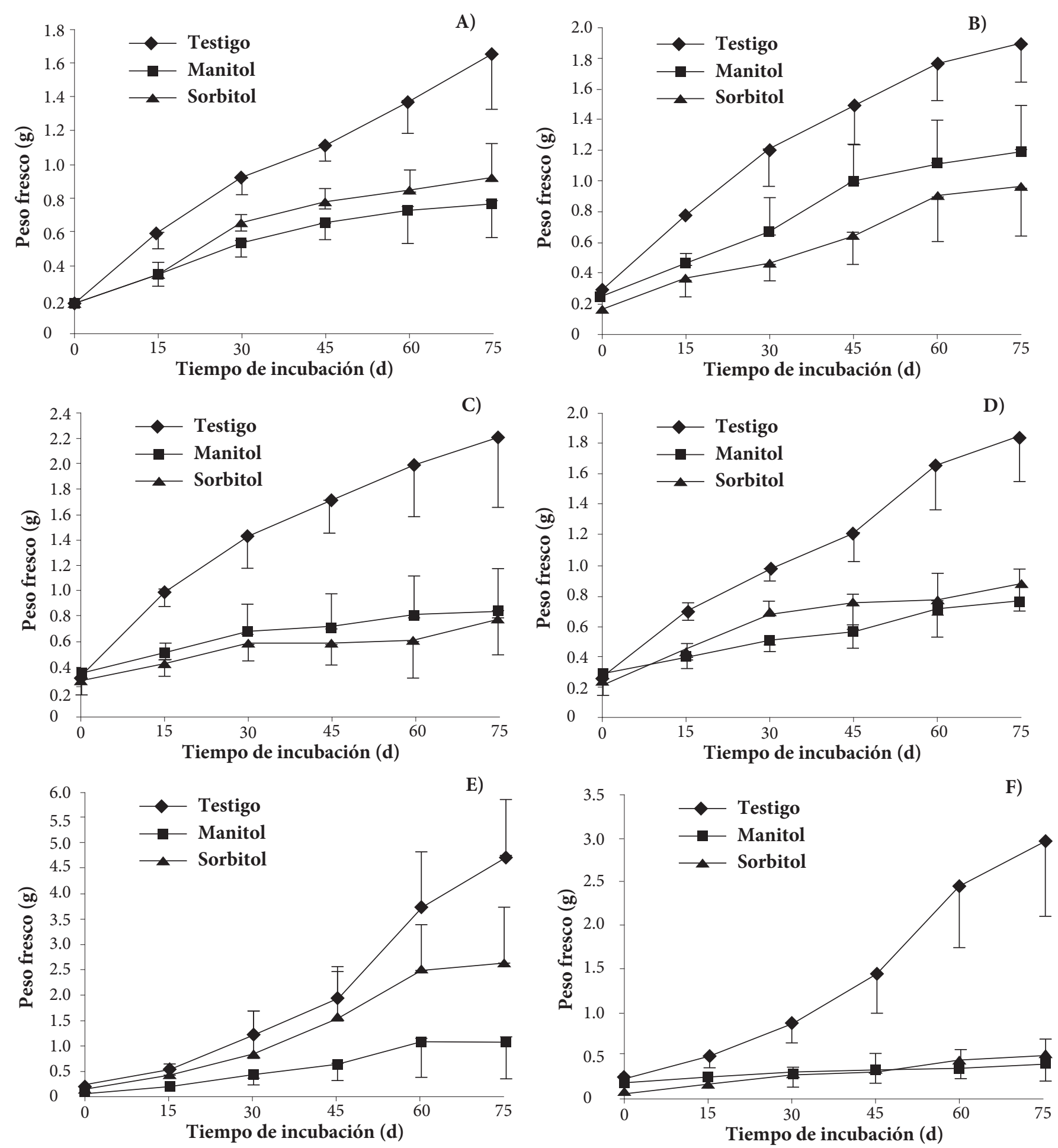

Figura 1. Efecto de los tratamientos probados para retardar el crecimiento en brotes de Agave bracteosa (A), A. chiapensis (B), A. cupreata (C), A. karwinskii (D), A. nizandensis (E), y A. ornithobroma (F). Barra = error estándar. 

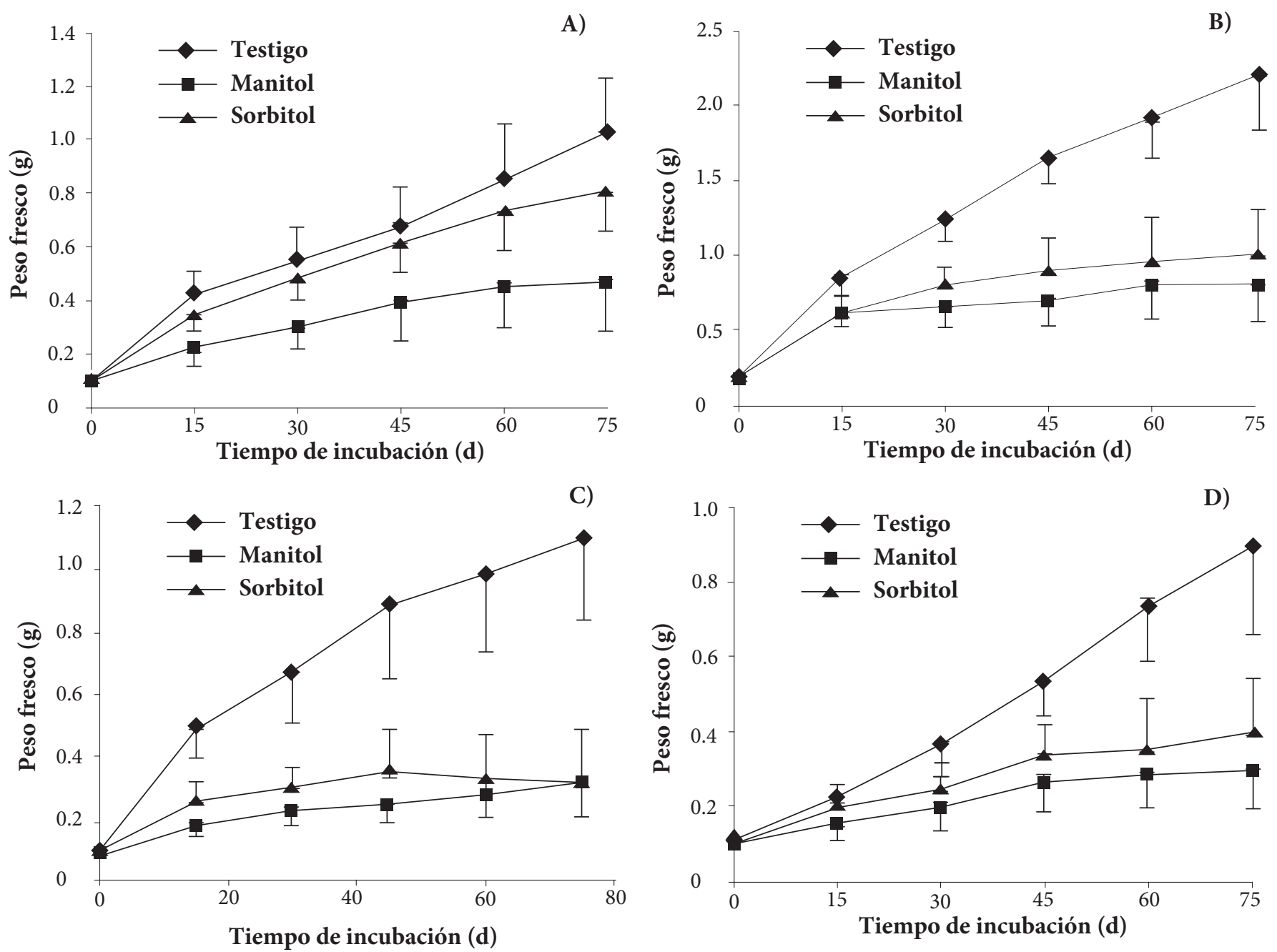

Figura 2. Efecto de los tratamientos probados para retardar el crecimiento en brotes de A. peacockii (A), y A. potatorum (B) A. titanota (C) y A. victoria reginae (D). Barra = error estándar.

El hecho de que los tratamientos aplicados no causaran mortalidad de los agaves se debe posiblemente a su adaptación a las zonas áridas. En la naturaleza, la disponibilidad de agua es la variable que más afecta la tasa de crecimiento de estas plantas, las cuales son capaces de disminuir esta tasa sin afectar su viabilidad en condiciones de baja disponibilidad de agua (Nobel y Quero, 1986). En este caso, las condiciones de alta y baja disponibilidad de agua, que determinan los ciclos de crecimiento y latencia en los agaves en la naturaleza, pueden ser reguladas mediante agentes osmóticos en los medios de cultivo in vitro.

En general, todos los brotes cultivados tanto en medio basal como en presencia de los agentes osmóticos, generaron un sistema radical durante el periodo de incubación. Algunas plantas generaron también brotes laterales (de 1 a 3), sobre todo en el medio testigo sin agentes osmóticos. Esta respuesta pudo deberse a la alta tasa de crecimiento en este medio, combinada con la actividad residual de las citocininas aquí empleadas para generar los brotes. Se co- noce que las citocininas sintéticas, como la benciladenina, mantienen una actividad residual en la base de los tallos de los brotes inducidos mediante su uso, esto aun después de transferidos a medios carentes de esta sustancia (Werbrouck et al., 1995).

En cuanto a la capacidad de regeneración de plantas completas a partir de tejidos conservados por 10 meses bajo los tratamientos descritos, en siete especies se observó que ésta no fue afectada por las estrategias aquí usadas para reducir el crecimiento (Cuadro 2). Esta era la respuesta esperada, ya que los sistemas de crecimiento retardado más eficientes son los que no afectan la capacidad de regeneración de los tejidos una vez que son transferidos a medios sin inhibidores. En Agave cupreata y A. peacockii, la capacidad de producción de brotes se redujo significativamente en los tejidos almacenados en medio con sorbitol, por lo que este agente no es el adecuado para la conservación a mediano plazo de tejidos, y que es preferible el uso de manitol. 


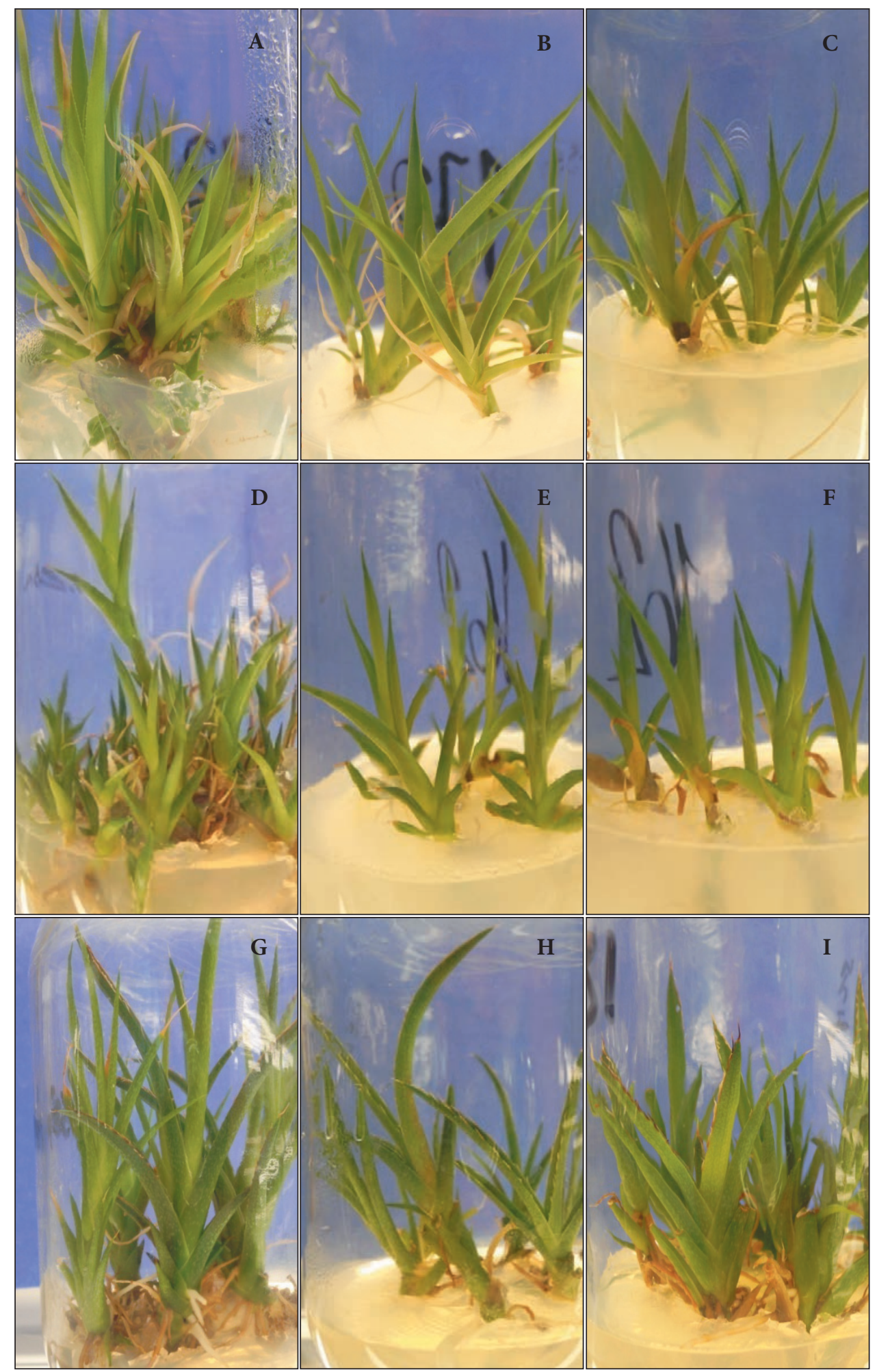

Figura 3. Brotes de $A$. bracteosa después de 75 días de incubación en medio basal (A), y en medio adicionado con manitol (B) y sorbitol (C); Brotes de $A$. nizandensis después de 75 días de incubación en medio basal (D), y en medio adicionado con manitol (E) y sorbitol (F); Brotes de A. victoria reginae después de 75 días de incubación en medio basal (G), y en medio adicionado con manitol (H) y sorbitol (I). 


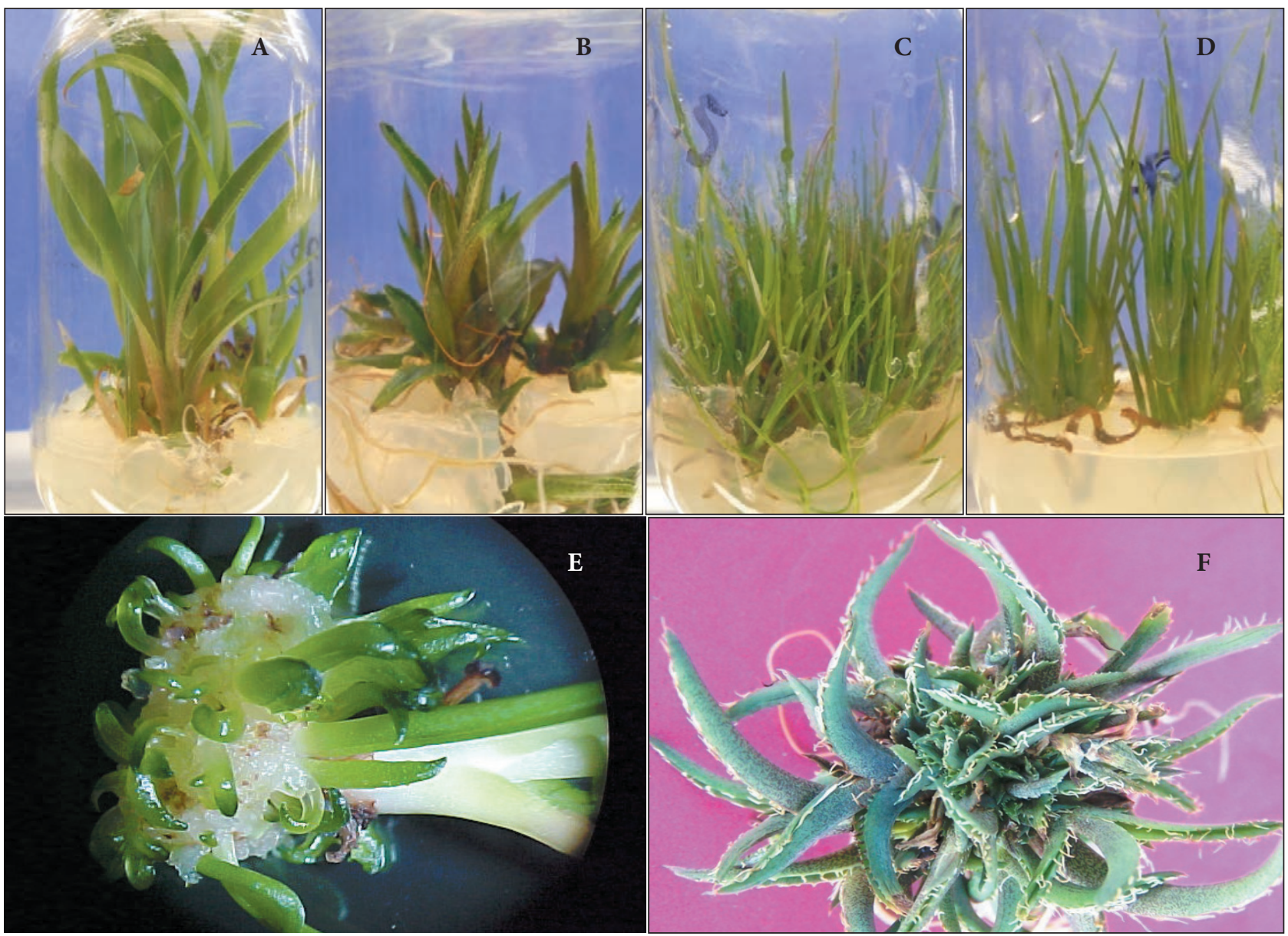

Figura 4. Brotes de $A$. cupreata después de 75 días de incubación en medio basal (A), y en medio adicionado con manitol (B); Brotes de A. ornithobroma después de 75 días de incubación en medio basal (B), y en medio adicionado con sorbitol (D); Primordios de brotes en un explante de A. chiapensis cultivado en un medio con $0.5 \mathrm{mg} \mathrm{L}^{-1} \mathrm{de} \mathrm{BA}$ (E) y Brotes bien diferenciados de $A$. peacockii generados en un medio con $0.5 \mathrm{mg} \mathrm{L}^{-1}$ de BA (F).

En A. ornithobroma, ambos agentes osmóticos disminuyeron significativamente la capacidad de los tejidos para generar brotes, por lo que es recomendable probar concentraciones menores a las usadas en este trabajo con el fin de encontrar la adecuada para esta especie en particular. En papa se recomiendan rangos de concentración de manitol o sorbitol de entre 20 y $40 \mathrm{~g} \mathrm{~L}^{-1}$ (Gopal, 2002), inferiores a los $50 \mathrm{~g} \mathrm{~L}^{-1}$ empleados en este trabajo. La aparición de primordios de brotes comenzó a observarse en la parte basal de los explantes desde la segunda semana después de su transferencia al medio de regeneración con citocininas y carente de agentes osmóticos (Cuadro 2) (Figura 4E), y a los $50 \mathrm{~d}$ ya eran visibles los brotes bien diferenciados (Figura 4F). La tasa de multiplicación más alta se observó en $A$. victoria reginae, con un promedio de 21.3 brotes por explante. La menor eficiencia fue la de A. karwinskii, que generó 5.7 brotes por explante. Estas eficiencias son similares a las reportadas para esta vía de regeneración en Agave (Domínguez-Rosales et al., 2008b).
Independientemente de la especie y de los tratamientos usados para retardar el crecimiento, se obtuvieron altas eficiencias de enraizamiento y adaptación a suelo. En promedio, $92 \%$ de los brotes generados produjeron un sistema radical vigoroso, y $80 \%$ de las plantas aclimatadas y transferidas a suelo sobrevivieron y se desarrollaron ex vitro (Cuadro 2). Se ha visto que el enraizamiento de los brotes no suele ser un problema en el género Agave, pues se puede lograr tanto en medio basal a su concentración normal, en medios diluidos, o con tratamientos con auxinas (Enríquez del Valle et al., 2005). En este trabajo el enraizamiento se logró con el medio basal diluido a 50 \% de su concentración normal, y no fue necesaria la inclusión de auxinas en el medio. La frecuencia de supervivencia y crecimiento en suelo de las plantas generadas en este trabajo fue también alta (Cuadro 2), y se encuentra dentro del rango reportado para este género (Domínguez-Rosales et al., 2008b). 


\section{CONCLUSIONES}

Se demostró que los sistemas de conservación in vitro de germoplasma en condiciones de crecimiento retardado causado por agentes osmóticos, como manitol y sorbitol, son eficientes en el género Agave. Estos compuestos retardaron el crecimiento sin afectar las respuestas morfogénicas de los tejidos mantenidos en su presencia. Por tanto, este sistema permite mantener colecciones de germoplasma viable con una mínima inversión de tiempo y recursos, ya que en condiciones normales estas especies deben ser transferidas a medio fresco cada $75 \mathrm{~d}$, mientras que con esta tecnología el periodo entre subcultivos puede prolongarse hasta 10 meses.

En cualquier momento los tejidos almacenados en condiciones de crecimiento retardado pueden ser transferidos a medios de regeneración para obtener la cantidad de plantas requerida. De esta forma es posible contar con una fuente ilimitada de material vegetal para diversos fines, como el establecimiento de cultivos para su explotación o su uso ornamental, sin necesidad de recurrir a la colecta de ejemplares silvestres.

\section{AGRADECIMIENTOS}

A la Universidad Autónoma de Aguascalientes por el apoyo financiero y facilidades brindadas para la realización de este trabajo (Proyecto PIBT-06-3).

\section{BIBLIOGRAFÍA}

Aureoles-Rodríguez F, J L Rodríguez-de la O, J P Legaria-Solano, J Sahagún-Castellanos, M G Peña-Ortega (2008) Propagación in vitro del «maguey bruto» (Agave inaequidens Koch), una especie amenazada de interés económico. Rev. Chapingo $\mathrm{S}$. Hort. 14:263-269.

Domínguez-Rosales M S, M L González-Jiménez, C Rosales-Gómez, C Quiñones-Valles, S Delgadillo-Díaz de León, S J MirelesOrdaz, E Pérez-Molphe-Balch (2008a) El cultivo in vitro como herramienta para el aprovechamiento, mejoramiento y conservación de especies del género Agave. Inv. Ciencia 41:5362.

Domínguez-Rosales M S, A G Alpuche-Solís, N L Vasco-Méndez, E Pérez-Molphe-Balch (2008b) Efecto de las citocininas en la propagación in vitro de agaves mexicanos. Rev. Fitotec. Mex. 31: $317-322$.
Eguiarte-Fruns L E, A González-González (2007) De genes y magueyes. Estudio y conservación de los recursos genéticos del tequila y el mezcal. Ciencias 87:28-35.

Engelmann F (2011) Use of biotechnologies for the conservation of plant biodiversity. In Vitro Cell. Develop. Biol.-Plant 47:5-16.

Enríquez del Valle J R, G Carrillo-Castañeda, J L Rodríguez-de la $\mathrm{O}$ (2005) Sales inorgánicas y ácido indolbutírico en el enraizado in vitro de brotes de Agave angustifolia. Rev. Fitotec. Mex. 28:175-178.

García-Mendoza A J (2007) Los Agaves de México. Ciencias 87:14-23.

Gentry H S (1982) Agaves of Continental North America. The University of Arizona Press. Tucson, Az., U.S.A. 670 p.

González-Benito M E, C Martín (2011) In vitro preservation of Spanish biodiversity. In Vitro Cell. Develop. Biol.-Plant 47:46-54.

Gopal J, A Chamail, D Sarkar (2002) Slow-growth in vitro conservation of potato germplasm at normal propagation temperature. Potato Res. 45:203-213.

Lynch P T (1999) Tissue culture techniques in in vitro plant conservation: In: Plant Conservation Biotechnology. Benson E E (ed). Taylor and Francis Ltd., London, UK. pp:41-62.

Murashige T, F Skoog (1962) A revised medium for rapid growth and bioassay with tobacco tissue culture. Physiol. Plant. 15:473-479.

Negri V, N Tosti, A Standardi (2000) Slow-growth storage of single node shoots of apple genotypes. Plant Cell Tiss. Org. Cult. 62: 159162 .

Nobel P S, E Quero (1986) Environmental productivity indices for a Chihuahuan desert Cam plant, Agave Lechuguilla. Ecology 67:1-11.

Noor N M, C W Kean, Y L Vun, Z A Mohamed-Hussein (2011) In vitro conservation of Malaysian biodiversity-achievements, challenges and future directions. In Vitro Cell. Develop. Biol.-Plant 47:26-36.

Perez-Molphe-Balch E, ME Pérez-Reyes, M L De la Rosa-Carrillo (2012) In vitro conservation of Turbinicarpus (Cactaceae) under slow growth conditions. Haseltonia 17:51-57.

Pilatti F K, T Aguiar, T Simões, E E Benson, A M Viana (2011) In vitro and cryogenic preservation of plant biodiversity in Brazil. In Vitro Cell. Develop. Biol.-Plant 47:82-98.

Ramírez-Malagón R, A Borodanenko, L Pérez-Moreno, M D SalasAraiza, H Nuñéz-Palenius, N Ochoa-Alejo (2008) In vitro propagation of three Agave species used for liquor distillation and three for landscape. Plant Cell Tiss. Org. Cult. 94:201-207.

Sarkar D, P S Naik (1997) Factors affecting minimal growth conservation of potato microplants in vitro. Euphytica 102:275-280.

Sarasan V, R Cripps, M M Ramsay, C Atherton, M McMichen, G Prendergast, J K Rowntree (2006) Conservation in vitro of threatened plants-progress in the past decade. In Vitro Cell. Develop. Biol.-Plant 42:206-214.

Watt M P, M Banasiak, D Reddy, E H Albertse, S J Snyman (2009) In vitro minimal growth storage of Saccharum spp. hybrid (genotype $88 \mathrm{H} 0019$ ) at two stages of direct somatic embryogenic regeneration. Plant Cell Tiss. Org. Cult. 96:263-271.

Werbrouck S P O, B Van der Jeugt, W Dewitte, E Prinsen, H A Van Oucke, P C Debergh (1995) The metabolism of benzyladenine in Spathiphyllum floribundum "Schott Petite" in relation to aclimatisation problems. Plant Cell Rep. 14:662-665.

Westcott R J (1981) Tissue culture storage of potato germplasm. 1. Minimal growth storage. Potato Res. 24:331-342. 